\title{
Forgetting history: The mnemonic consequences of listening to selective recountings of history
}

Memory Studies

2017, Vol. 10(3) 286-296

(C) The Author(s) 2017

Reprints and permissions:

sagepub.co.uk/journalsPermissions.nav DOI: $10.1177 / 1750698017701610$ journals.sagepub.com/home/mss

(S)AGE

\section{Charles B Stone}

John Jay College of Criminal Justice, USA

The Graduate Center, USA

The City University of New York, USA

\section{Theofilos Gkinopoulos}

Loughborough University, UK

\section{William Hirst}

The New School for Social Research, USA

\begin{abstract}
Our aim here is to delineate the connection between selective remembering and selective forgetting as it applies to lay historians listening to selective recountings of history. How does what a speaker remembers about a nation's past shape what is forgotten about the nation's past for the listener? To address this question, we will discuss psychological research demonstrating the mnemonic consequences of this selectivity with an emphasis on retrieval-induced forgetting within social settings. In particular, we highlight how selectively remembering nationally relevant, historical events may induce forgetting of related historical information for the listener, and this forgetting may not only have important implications for individual and national identities but said identities may influence both what is remembered and forgotten. We end with some concluding thoughts and areas of future research.
\end{abstract}

\section{Keywords}

forgetting, history, lay historian, remembering, selectivity, social

\section{Introduction}

In the last (2016) US presidential election, Donald Trump implored Americans to "make American great again," an explicit reference to a, perhaps mythical, historical past, but one that clearly had

\section{Corresponding author:}

Charles B Stone, Department of Psychology, John Jay College of Criminal Justice and The Graduate Center,

The City University of New York, 524 West 59th St, New York, NY 10019, USA.

Email: chstone@jjay.cuny.edu 
appeal. This essay is concerned with the consequences of such statements. Do statements about a historical past reshape memories? Here, the interest is not in its potential to reshape the memories of the person doing the remembering but of those attending to the act of remembering. Every act of remembering is selective. Some aspects of the past are recollected, whereas others are not. In referring, as he presumably was, to the great industrial giant America once was, Trump was recollecting one aspect of the American past while remaining silent about others, such as the United States' long-term embrace of slavery. Could Trump expect to change the memories Americans have of their nation's history by selectively evoking the past? (see also Ghilani et al., this issue). We want to answer this question by examining what psychologists know about selective remembering and its mnemonic effect on an audience. In particular, we are interested in this effect when both speaker and listener shared the same experience in the past or possess similar acquired knowledge. Americans presumably (albeit not all) had a fairly rich sense of American history before Trump ran for President of the United States. Will they have a different representation of their nation's past after listening to someone selectively recount this history, as Trump did? Does selective remembering on the part of a speaker reshape the already extant memories of their listeners?

We are particularly interested in how selective remembering might induce forgetting. It is probably not very surprising that selective remembering will reinforce the recollected memories, both in speaker and listener. What interests us here is the finding of psychologists that selective remembering can also induce selective forgetting of unmentioned but related memories, a phenomenon known as retrieval-induced forgetting (RIF). This phenomenon suggests that as Trump intones that he will "make America great again," the populace might be remembering a past in which workers in rust-belt industries flourished and, as a result, will reinforce these memories. However, as suggested by the RIF literature, can also suppress - that is, make less accessible - an America that condoned slavery, promoted segregation, and accepted the mistreatment of immigrants. The result is a reshaped memory of American history, with memories of an industrial giant becoming more accessible and memories of slavery, segregation, and the mistreatment of immigrants becoming less accessible.

To examine the plausibility of this possibility, we will first explore what psychologists have learned about the dynamics of selective remembering, inasmuch as selective remembering is a necessary precursor to the type of selective forgetting examined here. We will then turn to selective forgetting and show how this has been extended to individuals listening to the rememberer and how this research has implications and applications for how laymen remember a nation's history.

\section{Selective remembering}

There is little question that remembering is selective. One question for psychologists is why. That is, why don't people simply recall everything that they are capable of recalling? It turns out that it is not merely that people are lazy or simply find it easier to recall only some of what they know rather than everything that they know. Rather, selective remembering is a more motivated, social phenomenon.

\section{Goal-directed}

At an individual level, as Conway and Pleydell-Pearce (2000) have argued in the context of autobiographical memory, selective remembering occurs, in part, because remembering is goaldirected. These goals are often designed to support the current "working self," the conceptualization people have of themselves at any particular moment. Jane might view herself as "shy" at one particular moment and then have as mnemonic goal to remember past events that reinforce this view. 
As a consequence, she may neglect to recall instances in which she was friendly, instead, recalling those past events that support her view of herself as shy. Of course, at other moments, Jane might view herself as "friendly." Now, she will remember what she previously left unrecalled in terms of being friendly but fail to remember what she previously recalled in terms of being shy. In either case, the events she selectively recalls from her life — or selectively fails to recall—serve as support for her "working self."

As for nations, people will often speak of a nation as if it had a distinctive identity or if you like a self (Emerson, 1962; Turner, 1982). Just as psychologists ask people to fill in the blank when probed with "I am ___ when they assess how people conceive of themselves, so also can one ask people to fill in the blank when probed with "The US is__ "in order to assess how people conceive of their nation. A substantial body of literature on social identity indicates that people are quite capable of performing this latter task (Brewer, 1991). To be sure, not every American will fill in the blank in exactly the same way, but a consensus can emerge. For instance, most American conceived of the United States as a bastion of freedom (Foner, 2001). And like individuals, this is best characterized as a "working collective 'self'," in that how one conceives of the United States can change from one context to another. For example, after World War II (WWII), the United States thought of itself as a country that projects power into the world; it then retreated to a more isolationist perspective in the 1990 s and then in the 2000s once again viewed itself as projecting power.

As with autobiographical memory, it is possible that citizens of a county will often frame how they remember its history by having as a goal to remember past events that support their view of their nation (see also Bilewicz et al., this issue; Hilton and Liu, this issue). They may remember WWII but fail to remember the Vietnam War if their goal is see the United States as a nation that projects power. Alternatively, they may remember the Vietnam War but fail to remember WWII if their goal is to support the view that the United States should stay out of world affairs. In either instance, it is not that people may no longer have access to the unmentioned event. Rather, they simply do not bring it to mind because the goal they have does not require it.

\section{Audience tuning}

But selective remembering is not just about the mnemonic goals individuals might have. What people remember depends substantially on the audience they are addressing. Rememberers will tune what they remember to the audience at hand (Marsh, 2007; see also Echterhoff et al., 2005; Pasupathi et al., 1998; Tversky and Marsh, 2000). For instance, in a series of experiments (see Echterhoff et al., 2009, for a review), participants first learned about Michael and then are asked to convey to a third person what they know about Michael. If the third person is known to like Michael, the speaker will mainly convey positive attributes. Alternatively, if the third person is known to dislike Michael, they will mainly convey negative attributes. In another line of experimentation, researchers have shown that people include more details if they believe the audience is not knowledgeable about the topic at hand (see, for example, Adams et al., 2002). Moreover, they provide less specificity if the audience seems inattentive or unresponsive (see, for example, Pasupathi and Rich, 2005).

The same audience tuning will probably occur when one person talks to another person about their nation's history. For example, the extant research suggests (though it has yet to be shown) that a speaker should selectively tune their remembering of American history in a manner that stresses its greatness if they are talking to a Donald Trump supporter; they may emphasize the class struggles that have dominated American history if they are talking to a Bernie Sanders supporter. Similarly, research suggests that people should tell a detailed history to the nonhistorian and 
provide less specificity to trained historians. Of course, at times, one may provide an account of American history contrary to the expectations of the audience or tell a specific story to the historian or a vague story to a layperson. But, largely, as the extant research in domains other than history indicates, people tend to cater to their audience.

\section{Collaborative inhibition}

Selective remembering can arise, however, for more subtle interpersonal dynamics than suggested by audience tuning alone. For instance, when people recall a shared experience in a group, they tend to remember less than the sum of what each member of the group would remember individually, a phenomenon known as collaborative inhibition (Rajaram and Pereira-Pasarin, 2010). Researchers have found that they cannot account for this finding by relying on obvious explanations such as social loafing, the notion that, in a group, people will not try as hard at the task at hand because they think another member of the group will do the work for them (Weldon et al., 2000). Rather collaborative inhibition seems to arise chiefly because of retrieval blockage. In a standard collaborative inhibition experiment, two or more people first study a story and then are asked to recount the story jointly or individually. Given differences among people, each person in the group will probably encode the story differently during the initial study phase. One person will highlight one aspect of the story, whereas another person a different aspect. When one member begins to recall the story in the joint recounting, the retrieval strategies he or she pursues will reflect his or her unique encoding of the material. It may be an effective retrieval strategy for him or her but may not be optimal for other members of the group. As a result, the retrieval strategy one person adopts during the joint recounting will block the other group members' retrieval strategies. The results will be a less than optimal group recall, with the final recall probably reflecting the person who dominated the joint recounting (Rajaram and Pereira-Pasarin, 2010). Although it has not been tested using historical material, collaborative inhibition is extraordinarily robust and should be found when a group of people recount a nation's past, as well as when they recount shared past experiences or a shared stories they mutually learned. Interestingly, though, collaborative inhibition is not found when two experts are discussing material relevant to their expertise (e.g. two expert pilots discussing flight situations, Meade et al., 2009), suggesting that when professional historians recall history together, one might not see the selective remembering one observes with lay historians.

\section{Selective forgetting}

Clearly, people selectively remember the past, and this selective remembering has to do with both individual goals, an understanding of an audience, and the conversational dynamics during recall. Our chief interest, however, is not in how selective remembering can increase the mnemonic accessibility of the retrieved memories, but how it can also induce forgetting, that is, RIF.

\section{RIF}

As already noted, selective remembering may come at a cost. It can reinforce the recollected memories, but it can also induce forgetting. The phenomenon of RIF was first identified by Anderson et al. (1994). Although it has subsequently been shown to apply to a wide variety of material (stories, science essays, autobiographical memories, but, we should note, not history; see, for example, Barnier et al., 2004; Ciranni and Shimamura, 1999; Saunders and MacLeod, 2002; Shaw et al., 1995), the original work was done using word pairs (such to-be-remembered material is often used 
by psychologists because it allows them to control for such variables as frequency of occurrence). Because the original study well illustrates the phenomenon, we will describe it in some detail. In it, participants studied and learned category-exemplar pairs (e.g. fruit-apple, fruit-orange, vegetable-broccoli, and vegetable-pea). They then receive retrieval practice on half of the items (e.g. apple, not orange) from half of the categories (e.g. fruits, not vegetables). The experimenter controls what is practiced by providing the participant with the category name and the first two letters of one of the studied exemplars (e.g. fruit-ap___ The participant must then recall the exemplar (selective remembering or, as often referred to, selective practice). A final recall test follows, with participants attempting to recall all the originally studied exemplars (e.g. all the different fruits and all the different vegetables) after being given the category labels.

In the final recall, Anderson and colleagues found, not surprisingly, that selectively practiced items (e.g. apple) were remembered best. Less intuitively, though, is the finding that the unpracticed items related to the practiced items (e.g. orange) were remembered less well (less accessible) than the unpracticed, unrelated items (e.g. broccoli and pea). This pattern could not be explained by forgetting mechanisms such as decay. If the failure to practice an item allowed items to simply decay over time, then memories for unpracticed related items and the unpracticed unrelated items should be the same. That is, participants in the study should have remembered orange at about the same level that they remembered broccoli or pea. But, as we just indicated, this was not the case. Anderson and colleagues have attributed this pattern - more forgetting of unpracticed, related than unpracticed, unrelated memories - to inhibition (Anderson, 2003, but see Butler et al., 2001; Dodd et al., 2006; Jonker et al., 2015; Williams and Zacks, 2001, for other, less widely accepted explanations). When given the cue fruit-ap__ during the selective practice phase of the study, a number of alternatives may compete as a possible response. These might include, for instance, a multitude of possible fruits, including orange. In order to supply the correct answers, participants must inhibit (or suppress) competing responses such as orange, leaving only apple as an alternative. Unrelated items, such as pea and broccoli, should not produce the same response competition and hence should not be inhibited as one recalls apple. Inasmuch as inhibition lingers, on a subsequent memory test, the inhibited orange should be more likely to be less accessible than the uninhibited pea and broccoli.

\section{RIF in a social setting}

The phenomenon of RIF usually focuses on an individual in isolation. The person studies some material and then simply recalls it to him or herself (or perhaps an unseen experimenter). But we are interested here in the effect of selective remembering on an actively engaged audience, or to return to Mr Trump, the effect Trump's rendering of American history has on the memories the American public has of its history. Fortunately, the phenomenon of RIF has been studied in social settings as well. The results of these studies have clearly established that simply listening to someone selectively remember not only reinforced shared recollected memories but also induced forgetting for the unmentioned, related memories. That is, there is RIF for both the person doing the remembering (what might be called within-individual retrieval-induced forgetting (WI-RIF)) and for the person attending or listening to the remembering (i.e. socially shared retrieval-induced forgetting (SS-RIF); Cuc et al., 2007; see also Stone et al., 2012).

Cuc et al. (2007; see also Stone et al., 2010) began to experimentally examine SS-RIF by extending the extant WI-RIF literature to a social setting. In a typical experiment, two participants read a story and then jointly recounted it. A final memory test followed. The joint recounting was transcribed and coded for mentioned and unmentioned material from the original story, along with a note as to whether and when participants served as speaker or listener. From this coding, one 
could identify what was mentioned in the conversation, what went unmentioned, whether the unmentioned material was related or unrelated to the mentioned material, and finally, who said what or did not say it. In other words, one could assess whether there was RIF for speaker (WI-RIF) and listener (SS-RIF). The standard RIF patterns were found for both speakers and listeners in the final recall of each participant.

According to Hirst and colleagues, SS-RIF emerged because listeners concurrently, albeit covertly, retrieved with the speaker. With this concurrent, covert retrieval, the listener retrieved the same memories as the speaker and hence was more likely to inhibit unmentioned memories related to what the speaker recalled than unmentioned, unrelated memories. SS-RIF differs from WI-RIF in that SS-RIF occurred in the listener and, importantly, is optional. Listeners do not have to concurrently retrieve with a speaker, whereas speakers are, by definition, obligated to retrieve. As Kahneman (2013) noted, in his bestselling book, people are often cognitively lazy. They will avoid cognitively effortful tasks if they can. As a result, inasmuch as retrieval is effortful, the fact that listeners do, in many instances, concurrently retrieve is noteworthy. For example, our colleagues and we have found both WI-RIF and SS-RIF for autobiographical memories (Stone et al., 2013), flashbulb memories (Coman et al., 2009), controversial/political topics (Coman and Hirst, 2012), medical information (Coman et al., 2013), and fictional atrocities (Coman et al., 2014).

If concurrent retrieval is optional, we might not expect to find SS-RIF in all instances. One dimension on which concurrent retrieval, and hence SS-RIF, varies involves group membership and social identity (see also Sahdra and Ross, 2007, for a discussion of social identity and memory). This dimension might bear in interesting ways on the telling of history because history telling is often a means of buttressing social identity. In the first of two relevant studies, Coman and Hirst (2015) built on discussions of psychologists about the functions of remembering. These psychologists have argued that people talk about the past with others, in part, to enhance social bonds (Bluck et al., 2005). When Peter talks to Jane about how they first met, he probably does so not to check his memories but to create a sense of social intimacy with Jane. Coman and Hirst built on this observation and argued that, to continue with our example, Jane will concurrently retrieve with Peter, inasmuch as if she fails to do so, the goal of creating intimacy is unlikely to be achieved. Coman and Hirst posited that, by extension, one should expect listeners to concurrently retrieve if speaker and listeners are from the same group (i.e. someone they would like to create a social bond with) than if they are from different groups. In order to explore this possibility, they asked Princeton students to read a pamphlet that described a study abroad program and then to listen to a podcast of a student who had participated in the program. What the student recollected on the podcast was a selective rendering of what the Princeton participants in the study had just read. The major manipulation was the school membership of the person in the podcast. In order to manipulate group membership, they had in one condition the podcaster as a fellow Princetonian (i.e. a student from Princeton University; in another condition, as a Yalie (i.e. a student from Yale University). A final recall followed, in which the participants who had read the original pamphlet were asked to recall as much as they could about the study abroad program. Coman and Hirst found SS-RIF when the podcaster was a fellow Princetonian, but no evidence of SS-RIF when the podcaster was a Yalie.

If we extended Coman and Hirst's results to the telling of history, then one would expect that listening to an in-group member tell history will be more likely to induce forgetting for unmentioned, related information than listening to an out-group member. To return to Trump, the extant research suggests that his ability to induce forgetting with his selective remembering of history should be more likely among his supporters (presumably an in-group) than the opposition (presumably the out-group). But another study presents an important caveat. 
In this study, Coman et al. (2014) explored what they referred to as motivated recall. We have already noted that certain circumstances will lead a listener to concurrently retrieve with a speaker. But why don't they make the additional effort to remember what the speaker left unmentioned? Again, we turn to Kahneman's observation that people are often lazy. Why make the effort of retrieving unmentioned memories if you do not have to? Coman et al. speculated that there are times that one will make such an effort. Specifically, they posited that people will make the effort when a speaker leaves out certain aspects of the past that they find threatening to their social identity. In Coman et al., American participants first learned of several wartime atrocities committed by either American or Afghani soldiers as well as justifications for the atrocities. They then listened to someone selectively discuss the atrocity, with no mention of the justifications. In other words, the justifications were the unmentioned, related memories. A final test then occurred in which participants were asked to remember everything they first learned about the atrocities. When the perpetrator was an Afghani, Coman et al. found the expected SS-RIF for the justifications. The American participants concurrently retrieved with the person discussing the atrocity but did not make the effort to retrieve the unmentioned justifications. Alternatively, when the perpetrator was a fellow American, no SS-RIF was observed for the justifications. In this instance, the American participants clearly made the effort to recall them, even though they were unmentioned by the speaker. Coman et al. argued that their identity as an American was threated when Americans committed unjustified atrocities, hence the need to retrieve the unmentioned justifications.

When it comes to history, then, there may be limits to how much a selective rendering of the historical past can induce forgetting in those attending to this rendering. Induced forgetting may be greater if the person telling the story is viewed as an in-group member. Alternatively, if the social identity of the attendees is threatened, then they make an attempt to fill in the missing information. A recent study begins to examine these possibilities.

\section{Socially shared RIF and history}

Often the historical past is selectively remembered in the course of public speeches by public figures; again, Trump's 2016 campaign slogan is a succinct example of this. Critically, under certain circumstances, research suggests, just like the more laboratory-based stimuli discussed above, such selectivity can induce forgetting in the audience attending to the public speech.

In a study by Stone et al. (in preparation), Belgian citizens, both French speaking and Dutch speaking, were recruited to elicit six different facets associated with four different political/historical issues relevant to Belgium: linguistic (Belgium is composed of French, Dutch, and German speakers), historical, economic, and Brussels both before and after the Belgian King's yearly summer speech in 2012. As the case was, some of these individuals attended to the speech, others did not.

The researchers chose this period and speech because of its historic nature. As a result of political discord, from 13 June 2010 to 17 February 2011, Belgium set the record for a developed country to go with no elected government. It was only on 6 December 2011, Belgium finally inaugurated Elio Di Rupo (French speaker) as the Prime Minister of Belgium. Thus, the Belgian King's speech that summer held historic importance given the recent political turbulence/discourse in Belgium. (Note: the King's native language is French, an important point we will come back to.) As a result, Stone et al. were interested in whether the selectivity on the part of Belgian King might induce forgetting of related, political/historical information in those who attended to the speech relative to those who did not attend to the speech.

Overall, Stone et al. found SS-RIF for the French speakers. That is, the French-speaking Belgians who attended to the speech recalled less information related to what the Belgian King 
spoke about compared to those French-speaking Belgians who did not attend to the speech at all. For example, if the King discussed the topic "historical," the French-speaking participants who attended to the King's speech recalled fewer aspects surrounding the history of Belgium relative to those French-speaking participants who did not attend to the King's speech. However, for the Dutch-speaking participants, they found no such forgetting in those who attended to the speech relative to those who did not. Thus, on one hand, SS-RIF was found for French-speaking participants attending to the speech, and, on the other hand, SS-RIF was not found for those Dutchspeaking participants who attended to the King's speech.

These results provide a naturalistic extension of the SS-RIF phenomenon in both a historically important context and with historical information. Additionally, while further research is needed, these results also provide support for the importance of in-group membership for when SS-RIF is likely to occur. Given that the recently elected Prime Minister and the King are native French speakers, French-speaking Belgians may have been more inclined to retrieve along with the King and, thus, exhibit induced forgetting of related information. The Dutch speakers, alternatively, may have viewed the Prime Minister and the King as out-group members. And as retrieval on the part of the listener is optional, the Dutch speakers may not have concurrently retrieved along with the King (see, for example, Coman and Hirst, 2015). If, however, the King selectively discussed Belgium's colonization of the Congo (a potentially "threatening" topic), we may not have found SS-RIF for either the French- or Dutch-speaking participants in terms of justifications for why Belgium colonized the Congo (Coman et al., 2014). Again, further research is needed, but the present results speak to the importance of how listening to a speaker selective remembering the historical past can shape how the listeners remember said historical past as well as the potential power of social identity and how it may shape what is remembered or forgotten when historical events are selectively remembered.

\section{Concluding thoughts}

Although the research we have reviewed is only beginning to examine history, it does suggest that the selective remembering that characterized most "everyday" acts of remembering, which probably includes the rendering of history, can induce forgetting in those consuming the history. There is something paradoxical about such a result, in that it suggests that listening to someone tell a story about the past or reading history makes aspect of the past less accessible than if you had not bothered to listen or read about it in the first place. Active engagement in history can lead one to forget aspects of history one already knew (see also Klein et al., this issue).

However, the extant research also suggests that the presence or absence of SS-RIF will depend on a factor critical to many consumers of history, their social identity. It implies that SS-RIF is greater in consumers of history when the renderer of history is a within-group member than when he or she is an out-group member. Alternatively, leaving out information that might protect the consumer's social identity will not be an effective strategy for getting the consumer to forget the protected information. When social identity is threatened, the consumer of history will fill in what is left unmentioned.

Listening to or reading about history, then, is not a neutral affair. It sculpts one's memory. When it has the potential to enhance the social bonds one has with other members of one's community, it allows the consumer to forget what goes unmentioned. It permits, if you like, the consumer to come to share a representation of history similar to what the rendering conveys (see Stone et al., 2010). Alternatively, listening or reading historical events that threatens one's social identity has little chance of promoting a shared representation. The consumer resists and fills in what was left unmentioned. 
The recognition of the complex nature of the psychology underlying the consumption of history should not end with these observations. To better understand how selective remembering and forgetting shapes how the historical past is socially constructed, more research is needed. For example, does the selectivity on the part of history textbooks induce lay historians to forget related historical information differently from the selectivity of a fictional movie or the discussions with a friend? For example, might a textbook or history teacher's focus on less important historical details induce forgetting of more important historical details? (Goetz and Sadoski, 1995). What about forgetting at the institutional level, as evidence in the way history is conveyed in monuments or museums? (see, for example, Connerton, 2008). Might the selective nature of how a monument or museum is laid out induce forgetting in the visitors in a distinctive way? And if the answer to these questions is yes, how does such selective remembering and forgetting then shape lay historians' national identities? The answers to these questions will provide us with a greater understanding of how history is remembered and re-remembered among consumers of history.

\section{References}

Adams C, Smith MC, Pasupathi M, et al. (2002) Social context effects on story recall in older and younger women does the listener make a difference? The Journals of Gerontology, Series B: Psychological Sciences and Social Sciences 57: P28-P40.

Anderson CM, Bjork AR and Bjork LE (1994) Remembering can cause forgetting: retrieval dynamics in longterm memory. Journal of Experimental Psychology: Learning, Memory, and Cognition 20: 1063-1087.

Anderson MC (2003) Rethinking interference theory: executive control and the mechanisms of forgetting. Journal of Memory and Language 49: 415-445.

Barnier AJ, Hung L and Conway MA (2004) Retrieval-induced forgetting of emotional and unemotional autobiographical memories. Cognition \& Emotion 18: 457-477.

Bilewicz M, Witkowska M, Stefaniak A, et al. (2017) The lay historian explains intergroup behavior: examining the role of identification and cognitive structuring in ethnocentric historical attributions. Memory Studies 10(3): 310-322.

Bluck S, Alea N, Habermas T, et al. (2005) A tale of three functions: the self-reported uses of autobiographical memory. Social Cognition 23: 91-117.

Brewer M (1991) The social self: on being same and different at the same time. Personality and Social Psychology Bulletin 17: 475-482.

Butler KM, Williams CC, Zacks RT, et al. (2001) A limit on retrieval-induced forgetting. Journal of Experimental Psychology: Learning, Memory, and Cognition 27: 1314-1319.

Ciranni MA and Shimamura AP (1999) Retrieval-induced forgetting in episodic memory. Journal of Experimental Psychology: Learning, Memory, and Cognition 25: 1403-1414.

Coman A and Hirst W (2012) The propagation of socially shared retrieval-induced forgetting in social networks. Journal of Experimental Psychology: General 141: 321-336.

Coman A and Hirst W (2015) Social identity and socially shared retrieval-induced forgetting: the effects of group membership. Journal of Experimental Psychology: General 144(4): 717-722.

Coman A, Manier D and Hirst W (2009) Forgetting the unforgettable through conversation: socially shared retrieval-induced forgetting of September 11 memories. Psychological Science 20: 627-633.

Coman A, Stone C, Castano E, et al. (2014) Justifying atrocities: the effect of moral-disengagement strategies on socially shared retrieval-induced forgetting. Psychological Science 25: 1281-1285.

Coman D, Coman A and Hirst W (2013) Memory accessibility and treatment decision making for significant others: the role of socially shared retrieval induced forgetting. Frontiers in Behavioral Neuroscience 7: 72.

Connerton P (2008) Seven types of forgetting. Memory Studies 1: 59-71.

Conway MA and Pleydell-Pearce CW (2000) The construction of autobiographical memories in the selfmemory system. Psychological Review 107: 261-288. 
Cuc A, Koppel J and Hirst W (2007) Silence is not golden: a case for socially shared retrieval-induced forgetting. Psychological Science 18: 727-733.

Dodd MD, Castel AD and Roberts KE (2006) A strategy disruption component to retrieval-induced forgetting. Memory \& Cognition 34: 102-111.

Echterhoff G, Higgins ET and Groll S (2005) Audience-tuning effects on memory: the role of shared reality. Journal of Personality and Social Psychology 89: 257-276.

Echterhoff G, Higgins ET and Levine B (2009) Shared reality: experience commonality with others' inner states about the world. Perspectives in Psychological Sciences 4: 496-521.

Emerson R (1962) From Empire to Nation: The Rise to Self-Assertion of Asian and African People. Boston, MA: Beacon Press.

Foner E (2001) American freedom in a global age. The American Historical Review 106: 1-16.

Ghilani D, Luminet O, Erb H-P, et al. (2017) Looking forward to the past: an interdisciplinary discussion on the use of historical analogies and their effects. Memory Studies 10(3): 274-285.

Goetz ET and Sadoski M (1995) Commentary: the perils of seduction: distracting details or incomprehensible abstractions? Reading Research Quarterly 30: 500-511.

Hilton D and Liu J (2017) History as a narrative of the people: from function to structure and content. Memory Studies 10(3): 297-309.

Jonker TR, Seli P and MacLeod CM (2015) Retrieval-Induced forgetting and context. Current Directions in Psychological Science 24: 273-278.

Kahneman D (2013) Thinking, Fast and Slow. New York: Farrar, Straus and Giroux.

Klein O, Hegarty P and Fischhoff B (2017) Hindsight 40 years on: An interview with Baruch Fischhoff. Memory Studies 10(3): 249-260.

Marsh JE (2007) Retelling is not the same as recalling: implications for memory. Current Directions in Psychological Science 16: 16-20.

Meade ML, Nokes TJ and Morrow DG (2009) Expertise promotes facilitation on a collaborative memory task. Memory 17: 39-48.

Pasupathi M and Rich B (2005) Inattentive listening undermines self-verification in personal storytelling. Journal of Personality 73: 1051-1086.

Pasupathi M, Stallworth ML and Murdoch K (1998) How what we tell becomes what we know: listener effects on speakers' long-term memory for events. Discourse Processes 26: 1-25.

Rajaram S and Pereira-Pasarin L (2010) Collaborative memory: cognitive research and theory. Perspective on Psychology Sciences 5: 649-663.

Sahdra B and Ross M (2007) Group identification and historical memory. Personality and Social Psychology Bulletin 33: 384-395.

Saunders J and MacLeod DM (2002) New evidence on the suggestibility of memory: the role of retrievalinduced forgetting in misinformation effects. Journal of Experimental Psychology: Applied 8: 127 142.

Shaw JS, Bjork RA and Handal A (1995) Retrieval-induced forgetting in an eyewitness memory paradigm. Psychonomic Bulletin and Review 2: 249-253.

Stone CB, Barnier JA, Sutton J, et al. (2010) Building consensus about the past: schema consistency and convergence in socially shared retrieval-induced forgetting. Memory 18: 170-184.

Stone CB, Barnier JA, Sutton J, et al. (2013) Forgetting our personal past: socially shared retrievalinduced forgetting of autobiographical memories. Journal of Experimental Psychology: General 142: 1084-1099.

Stone CB, Coman A, Brown AD, et al. (2012) Toward a science of silence: the consequences of leaving a memory unsaid. Perspectives on Psychological Science 7: 39-53.

Stone CB, Luminet $\mathrm{O}$, Licata L, et al. (in preparation) Public speeches induce "collective" forgetting? The Belgian King's 2012 summer speech as a case study.

Turner JC (1982) Towards a cognitive redefinition of the social group. In: Tajfel H (ed.) Social Identity and Intergroup Relations. New York: Cambridge University Press, pp. 15-400.

Tversky B and Marsh EJ (2000) Biased retellings of events yield biased memories. Cognitive Psychology 40: $1-38$. 
Weldon S, Blair C and Heubsch PD (2000) Group remembering: does social loafing underlie collaborative inhibition? Journal of Experimental Psychology: Learning, Memory, and Cognition 26: 1568-1577.

Williams CC and Zacks RT (2001) Is retrieval-induced forgetting an inhibitory process? American Journal of Psychology 114: 329-354.

\section{Author biographies}

Charles B Stone is an assistant professor in the Department of Psychology, John Jay College of Criminal Justice and The Graduate Center, The City University of New York, USA.

Theofilos Gkinopoulos is a PhD student in the Department of Social Sciences, Loughborough University, UK.

William Hirst is the Malcom B. Smith Chair and Professor of Psychology at the New School for Social Research, USA. 